\title{
Implementation of "ADAB" to Hearing Impaired Student as Learning Innovation in the Data and Text Mining Course, Information System Distance Learning, Binus Online Learning
}

\author{
https://doi.org/10.3991/ijet.v15i05.12147 \\ Teguh Prasandy $(\bowtie)$, Ika Nurlaila, Titan, Lena \\ Bina Nusantara University, Jakarta, Indonesia \\ Bina Nusantara University, West Jakarta, Indonesia \\ teguh.prasandy@binus.edu
}

\begin{abstract}
Not withstanding every human being's wish to be born perfect both physically and emotionally, some have no luck being born with physical barriers, further referred as persons with disabilities. The disabilities can take a form as hearing impaired. We, at Distance Education Binus Online Learning (BOL), were keen to observe the implementation of ADAB (Ayo Dengar Ayo Bicara) To Connect application for hearing-impaired students in video conference sessions. The current study was aimed at seeking learning model innovations in data and text mining courses as well as measuring impacts of ADAB to Connect application to hearing-impaired students' academic performances. It was observed that by implementing the application, the students' academic performance was elevated to $90 \%$. We, therefore, are convinced that this learning innovation worths further study and improvisation.
\end{abstract}

Keywords-ADAB, hearing-impaired, distance-earning, innovation

\section{Introduction}

Not all children are born in physical and spiritual perfection. Although this perfection is everyone's dream, it cannot be denied that some are born with physical limitations or are called persons with disabilities. A form of physical impairment is hearingimpaired. The right to receive good education is also the property of those with disabilities or special needs, both physical and developmental disabilities, as laid down in Law 5 of 2003 on the national education system in Article 5 (2), which states that " Citizens with physical, emotional, mental, intellectual and / or social disabilities are entitled to special education. "The availability of education that can support people who are still limited, especially for those with special needs. (0) According to Law No. 8 of 2016, persons with disabilities are any person who experiences physical, intellectual, mental and / or sensory disabilities for a long period of time, who interact with the environment and may experience obstacles and difficulties in fully and effectively participating. contact with other citizens on the basis of equal rights (1). 
PUSDATIN (Center of Data and Information) of The Ministry of Social Affairs in 2010 demonstrated that there were 11,580,117 people with disabilities in Indonesia. Among those as many as 3,474,035 people were visual-impaired, 3,010,830 were extremity-impaired, 2,547,626 were hearing-impaired, 1,389,614 were mentalimpaired and the least were 1,158,012 people with chronic disability (2).

Hearing impaired include deafness and hearing loss. Deafness is defined as inability to hear sounds in $70 \mathrm{~dB}$ or more. Worse than that is hearing loss when power of hearing sounds within the range 16-69 dB is totally gone. These obstacles would not allow hearing-impaired students to understand speech thus linguistic information could not be processed properly (3) . This is, of course, not of justification in any way to lower their fundamental rights to experience education at all levels without deliberate discrimination, neglection or exploitation (1).

One speech recognition driven directory assistance service was once built by Google in 2006 and named after GOOG-411. It was launched for, mainly, the US market and would work from any phone. Since the smartphone platform emerged as a winning phone transformation, such as iPhone and Android operating system like Nexus One, the application of speech recognition system has shifted Google's orientation to provide speech input for the Search by Voice engine on these smartphones (4).

In 2015, Hsieh and Liu built a training system termed as CAST (computer-assisted speech training) that benefitted sensorineural-hearing loss (SNHL) to recognize monosyllabic words and consonants (5). Yet, overall, study conducted to assist hearingimpaired people overcome their burden is considerably limited. Communication applications that meets all the features recommended by research devices were not available (6).

BINUS as 3-star ranked university by QS created a speech-into-text application to, specifically, help students with hearing impairment to achieve as great as their normal counterpart fellows. To implement three out of its seven institution's values being that strive for excellence, respect and innovation, BINUS has been persistently improving supporting facilities for hearing-impaired students through which the students may achieve academically and socially. To date, BINUS has seven hearing-impaired undergraduate students majoring different study programs: two at the School of Design, a student at the Department of Architecture, a student at the Department of Japanese Literature, a student at the Department of Management and a student at Binus Online Learning. Despite the smallness of hearing-impaired students' number, BINUS University persistently provides its top learning services towards them all. BINUS Online Learning (BOL), in particular, has been offering discussion forums as well as video conferences with texts underneath to speed up knowledge transfers and dissemination and to elevate post-lecture understanding of the students. Most recently, BOL developed an application called ADAB (Ayo Dengar Ayo Bicara/ Let's play Let's Talk). This was specifically aimed at helping students to read lip movements from lecturers during video conferences.

Earlier, Google had built an Application Programming Interface (API) function called Speech to Text via Android application. This application catches every statement then converts it into text. API, further, generated a few of downstream applications for Google Transcribe, U-dictionary and Speech to Text on Whatsapp. The latest 
mentioned inspired development of the ADAB to Connect application which allowed hearing-impaired students to deliver and present their presentation subjects normally. We, therefore, opted to focus on the implementation of the application in the Data and Text Mining course in the online distance learning system in BINUS in this current study.

\subsection{Study formula}

In the current study, we question:

i) How to implement "ADAB to connect" application to hearing-impaired undergraduate students registered at BOL in video conference sessions? Has ADAB to Connect application been helpful to drive academic performances of the hearingimpaired undergraduate students towards excellence as were exhibited by those normal-counterpart students?

Scope of study: The scope of our study was one cycle assessment of ADAB to Connect implementation to hearing-impaired undergraduate students in BOL's classroom activity.

ii) Primary objectives we were keen to achieve in the study were to be able to elaborate learning model innovation in regards with data and text mining subjects and to be able to effectively apply ADAB to Connect for hearing-impaired undergraduate student?

\section{Research Methodology}

We applied a method referred to as Classroom Action research (CAR). This method is commonly used for learning quality assessment. CAR is focused on the class or on the learning process that occurs in the classroom (Wijaya \& Syahrum, 2013).

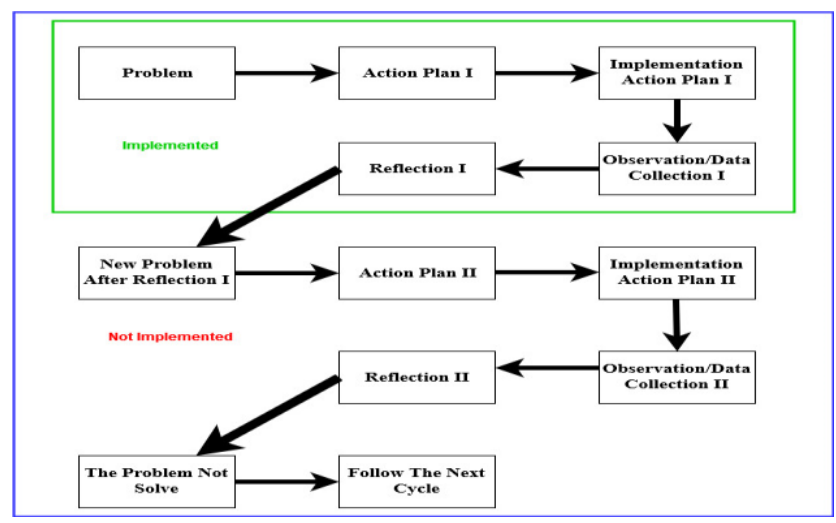

Fig. 1. PTK source activity cycle (Wijaya \& Syahrum, 2013) 


\subsection{Issues}

We, up to date, have few hearing-impaired students taking class of Data and Text mining course in our distance learning information system joined class of TGBA . The class is conducted through learning management system and video conferences where students are required to interact personally with the tutors or lecturer. This needs more efforts for the students have to be able to read the tutor's or lecturer's lip movements to enable them process delivered subjects. We found out that this was not automatically easy for them. ADAB to Connect application was built to address this challenge.

\subsection{Action planning 1}

Action Plan 1 on this study including:

- To measure the level of hearing impairment of the students according to the tools the students use

- To deliver lecture subjects through video conference as usual

- Both Lecturers and students are asked to install ADAB To Connect application in their smartphone

- Apply ADAB to Connect in the second video conference session.

\subsection{Implementation of action 1}

Action Plan 1 is executed following below described:

- Log in to the application with individual protected account

- Prior to activation, class and learning sessions are free to select

- The lecturers attach a headset to the smartphone

- Lecture subjects are delivered as usual

- Students are urged to participate in video conference by reading texts generated by the ADAB application popped up on the phone screens

\subsection{Data collection}

We collected data from video conference recorded from both tutor/lecturer's and students' print screen:

Reflection in this study are:

- To view students' responses during the use of $\mathrm{ADAB}$ to Connect application

- Assess the understanding level of the students after joining ADAB to Connectaided video conference sessions. 


\section{Results}

\subsection{Result implementation of actions 1}

The students, when were challenged with voice at approximately $70 \mathrm{~dB}$, found the voice was still audible albeit weak. However, when the speed of speaking was risen, they were losing their ability to capture the voice. This made a complete sense for they solely counted on the lip movements from the lecturers to process linguistic information. Once this is missed albeit partly, their understanding might be disturbed.

Some hardness on recording orally delivered subjects can be seen in Fig.2 and Fig.2.

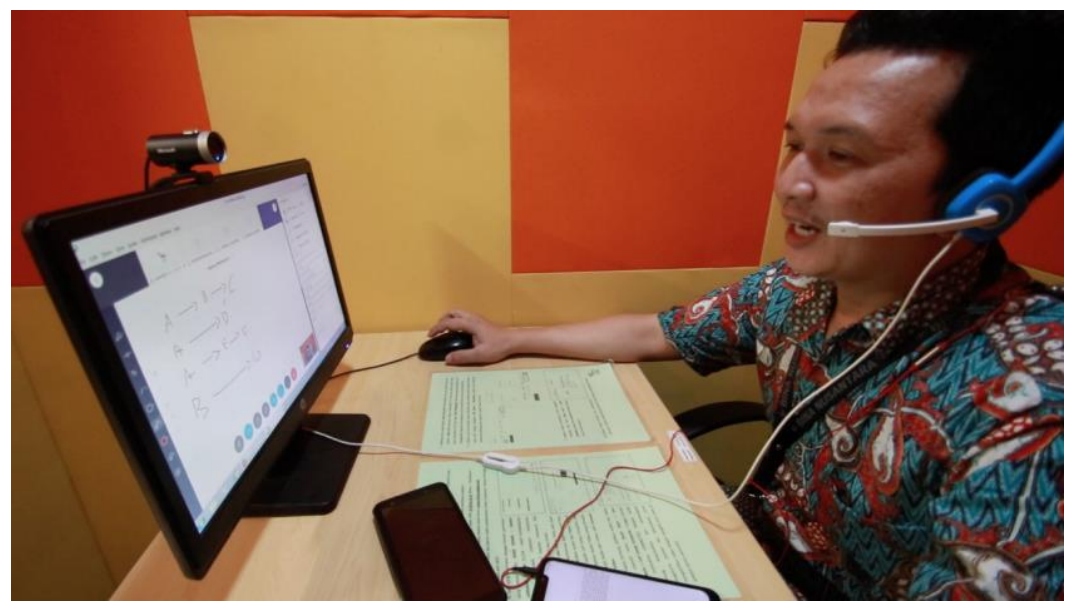

Fig. 2. A lecturer conducting video conference without $A D A B$ to Connect

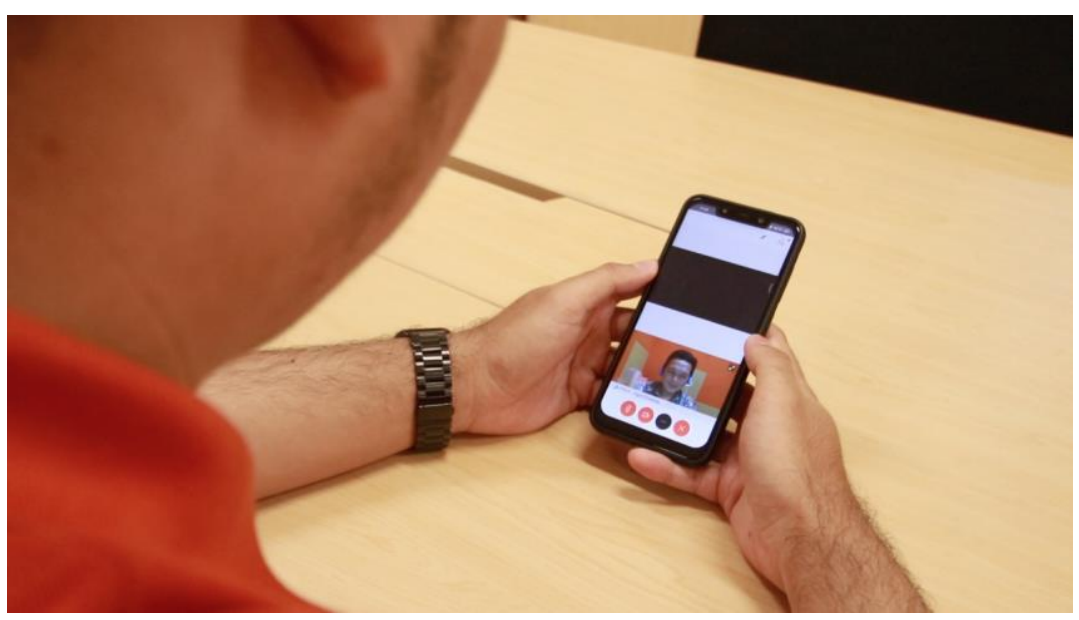

Fig. 3. A student joining video conference without $\mathrm{ADAB}$ to Connect 
It is demonstrated in Fig. 2 and Fig. 3 that without assistance from ADAB to Connect application, the students were facing troublesome to digest spoken lessons because they were unable or missing the lip movements of the lecturers. Result of Data Collection

In session 2, both lecturers and hearing-impaired students, whom prior access were granted, applied ADAB to Connect, simultaneously. While to the lecturers the application functioned to convert their spoken words into texts, to the students it provided texts through which they could read and process the given information as if they were nondisabled students. The word-capturing followed by into-text-converting would occur in the entire video conference session as pictured in Fig.4.

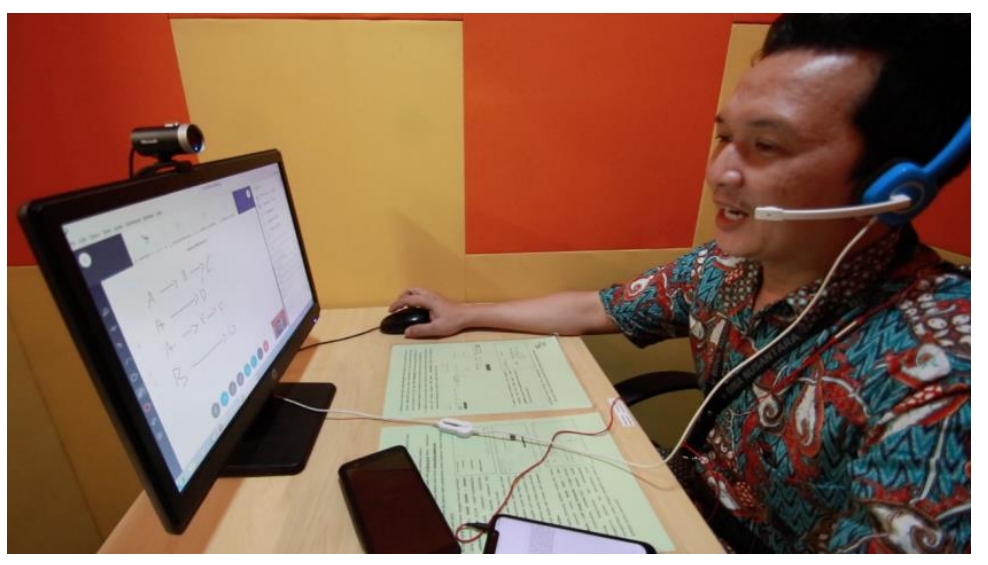

Fig. 4. The lecturer is applying ADAB to Connect to deliver his subject materials

The lecturer conducts teaching session as usual. The only difference is at tbe intervention of $\mathrm{ADAB}$ to Connect application that work to transform spoken words into texts real-time.

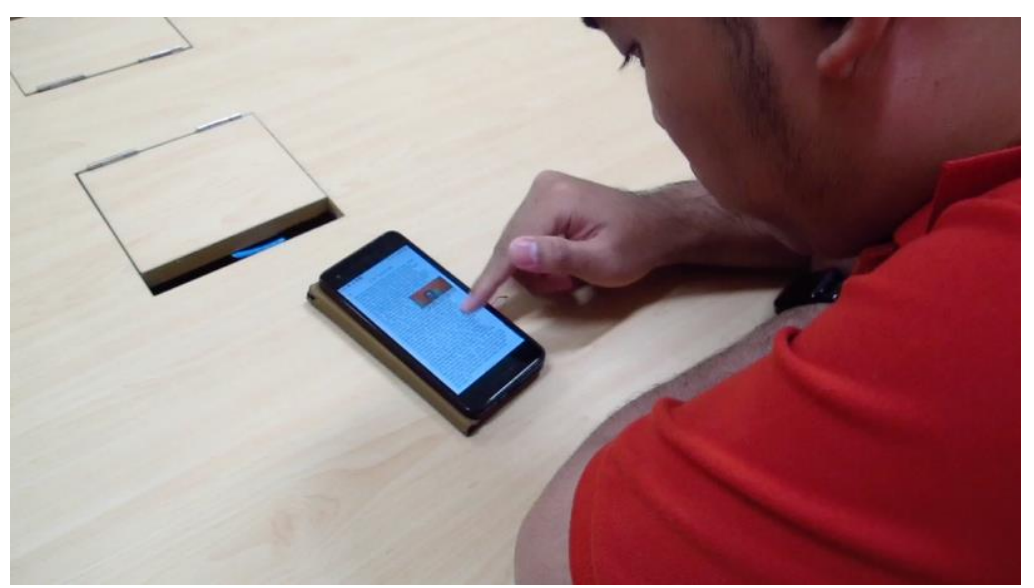

Fig. 5. The student is applying ADAB to Connect application 


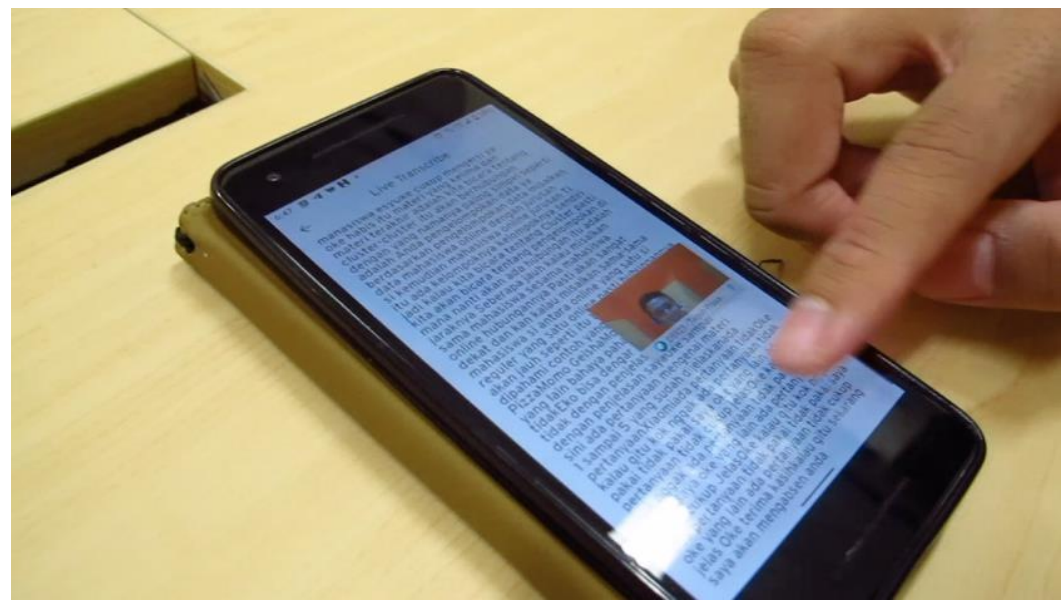

Fig. 6. Screen view of ADAB to Connect Application displayed on the students' smartphone

\subsection{Result reflection}

After the completion of video conference session, the subject dissemination by the students via $\mathrm{ADAB}$ to Connect application was measured. It was found that such appplication helped enhancing the subject dissemination among the students as much as $90 \%$. The students could re-access the video conferences later whenever they need it.

\section{Discussion}

$\mathrm{ADAB}$ to Connect application is intended to help students with hearing impairment to improve their understanding upon subjects which were orally presented mainly through video conferences.

Compared to the Google application (please specify the name), the ADAB to Connect application is more sensitive than any statement made by the teacher, so that students can follow the material better, if only by reading.

The use of these applications can be used as learning innovation in the PJJ Online learning information system for students with special needs, especially for hearingimpaired students. The things that need to be done are to add fields to the course overview for students with disabilities, consisting of the type of disability, the level of disability and disability characteristics. In addition to the overview course also added to the self-study program design in the column with the self-study phase and the selfstudy strategy on using ADAB to connect, especially in the week with a video conferencing session. so that teachers give courses at Binus Online Learning. 


\section{The conclusion}

We conclude that the implementation of $\mathrm{ADAB}$ to Connect application in the course of Data and Text Mining allow hearing-impaired students to follow and to achieve an undestanding level as good as the normal counterpart students towards the given lecture. The acceptance level of such an application was observed at a level of $90 \%$. Although we found it promising, we still urge ourselves to make evaluationbased improvement by times.

\section{Acknowledgement}

General Director Pensus Belmawa DIKTI to fully fund this article.

\section{$7 \quad$ References}

[1] الثع Undang-Undang Republik Indonesia Nomor 8 Tahun 2016. Salinan Undang Republik Indones Nomor 8 Tahun 2016 Tentang Penyandang Disabil. 2016;147:11-40. https ://doi.org/10.31219/osf.io/xtdba

[2] Kementrian Kesehatan Republik Indonesia. Infodatin_Disabilitas.Pdf. Penyandang Disabilitas Pada Anak. 2012.

[3] El-Zraigat IA. Assessing special needs of students with hearing impairment in Jordan and its relation to some variables. Int Educ Stud. 2013;6(2):63-75. https://doi.org/10.5539/ies.v $\underline{6 n 2 p 63}$

[4] Schuster M. Speech recognition for mobile devices at Google. Lect Notes Comput Sci (including Subser Lect Notes Artif Intell Lect Notes Bioinformatics). 2010;6230 LNAI(August 2010):8-10.

[5] Hsieh D-L, Liu T-C. Effect of Computer-Assisted Speech Training on Speech Recognition and Subjective Benefits for Hearing Aid Users with Severe to Profound Prelingual Hearing Loss. J Commun Disord Deaf Stud Hear Aids. 2015;03(04). https://doi.org/10.4172/2375$\underline{4427.1000144}$

[6] Alnfiai M, Sampali S. Social and Communication Apps for the Deaf and Hearing Impaired. 2017 Int Conf Comput Appl ICCA 2017. 2017;(December):120-6. https://doi.org/1 $\underline{0.1109 / \text { comapp. } 2017.8079756}$

\section{Authors}

Teguh Prasandy is a Lecturer at Information System Distance Learning Program, BINUS Online Learning (BOL). BINUS University, J1. KH. Syahdan No. 9, Palmerah, Jakarta Indonesia. He Work as Online Lecturer Coordinator, on Knowledge Group Business Competitive Intelligence specialization on database system.

Ika Nurlaila is a senior researcher at Bioinformatics and Data Science Research Center, Bina Nusantara University. She mainly works on cancer-associated big data as well as immune system-related Biology models. In Distance Learning System 
(BOL), she has been assigned permanent lecturer for Research and Methodology subjects. (ika.nurlaila@binus.edu)

Titan is a Head of Program Information at Information System Distance Learning, BINUS Online Learning (BOL). BINUS University, Jl. KH. Syahdan No. 9, Palmerah, Jakarta Indonesia. He also lecturer for information system analysis and design also advance topic in information system. (titan@binus.edu)

Lena is a senior manager and service planning leader in Samsung R\&D Institute Indonesia. She also lecturer for User Experience subject on Information System Distance Learning, Binus Online Learning. (phingz@gmail.com)

Article submitted 2019-10-31. Resubmitted 2019-12-06. Final acceptance 2019-12-08. Final version published as submitted by the authors. 